\title{
ДИСКУССИИ
}

\section{Корпоративное управление: направления дискуссий}

\author{
Животова Е.Л. ${ }^{71}$, Солнцева М.С. ${ }^{72}$, Степанова А.Н. ${ }^{73}$
}

27-28 ноября 2008 года Европейский институт исследований в области менеджмента (European Institute of Advanced Management Studies) провел 5-ю Международную конферениию по корпоративному управлению в Брюсселе (Бельгия). B конференции приняли участие более 50 ученых из разных уголков Европы. Представители 25 стран сделали доклады на темы, ассочиированные с различными аспектами корпоративного управления.

Конференция была подразделена на четыре секиии, возглавляемые учеными с мировыми именами. Профессор Мартин Хилб (Martin Hilb), из Университета Сент-Галлена в Швейцарии (IFPM Center for Corporate Governance, University of St Gallen), и Toмac Kacac (Tomas Casas) uз IFPM-CCG (Шанхай) курировали секцию, посвященную проблемам международного корпоративного управления. Профессор Хью Гроув (Hugh Grove) из Университета Денвера (University of Denver, USA) и Лаура Cnupa (Laura Spira) из бизнесшколь Университета Оксфорд Брукс (Oxford Brookes University) возглавили секиии, посвященные деятельности совета директоров и стратегическому контролю.

В ходе конференщии был представлен ряд работ, посвященных проблемам государственного регулирования корпоративного управления и раскрытия информации. Эта проблематика является одной из наиболее актуальных сегодня в свете проиессов глобализаџии и очевидной неразвитости законодательства в области корпоративного управления. В рамках секции прозвучал совместный доклад Фердинандо ди Карло (Ferdinando di Carlo) и Оливье Бутзбака (Olivier Butzbach) из Naples Second University на тему «Влияние государственного регулирования учета опщионов: сравнительный анализ на европейских данных». Симона Франицони (Simona Franzoni) из Brescia University (Италия) представила работу, посвященную изучению вознаграждений исполнительных директоров компаний. Лиза Викторавич под научным руководством доктора Хью Гроува представила работу, посвященную требованиям $к$ корпоративному управлению для листинговых компаний.

Основная масса представленных работ сделана на базе европейских компаний. Одна из ключевых тематик - изучение различных подходов $\kappa$ корпоративному управлению $u$ сопоставление разных моделей корпоративного управления. Один из наиболее ярких докладов по данной тематике был представлен самыми активными участниками конференции, учеными из Италии. Фабрицио Бава (Fabrizio Bava) и Алан Деваль (Alain Devalle) из Torino University, выступили с докладом, посвященным новой модели корпоративного управления компании «Пармалат».

Большое внимание было уделено проблемам корпоративного управления на развивающихся рынках. Индийский ученый Сушил Ханна (Sushil Khanna) представил результаты совместной работь с коллегой из Университета Цинциннати (University of Cincinnati) Прадьоттом Сеном (Pradyot Sen). С докладом, посвященным особенностям исламской системы корпоративного управления, выступил Сунил Хандельваль (Sипіl

\footnotetext{
${ }_{71}^{71}$ Стажер-исследователь научно-учебной лаборатории корпоративных финансов ГУ-ВШЭ.

72 Преподаватель, младший научный сотрудник научно-учебной лаборатории корпоративных финансов ГУВШЭ.

${ }^{73}$ Преподаватель, младший научный сотрудник научно-учебной лаборатории корпоративных финансов ГУВШЭ.
} 
Khandelwal) из ОАЭ. Владимир Маринкович представил работу на тему «Корпоративное управление в переходный период - трудности и перспективы - на примере Сербии». Что касается работ на примере развиваюшихся стран Южной Америки, Жозе Варгас (Јоsе Vargas) из Технологического института Гузмана (Instituto Tecnologico de CD Guzman) представили работу, посвященную аспекту структуры собственности в трансформации корпоративного управления в Мексике.

Ряд концептуальных исследований, представленных в ходе конференции, посвящен тематике, находящейся на стыке корпоративных финансов и корпоративного управления, а именно изучению влиянию корпоративного управления на эффективность деятельности компании. С докладом, посвященном эффективности корпоративного управления в китайских банках, выступила Манли Фу (Manli Fu) из Университета Сент-Галлена (St Gallen University, Switzerland). Результаты обширной работы были продемонстрировань представителями университета Высшая школа экономики (Москва) Ириной Ивашковской и Анастасией Степановой. Они представили результаты исследования, изучающего влияние финансовой архитектуры компании на ее корпоративную эффективность на данных крупнейших компаний из восьми европейских стран.

Фелечиио Жозе Аугусто (Felicio Jose Augusto) из португальского университета ISEG School of Economics and Management (Португалия) вместе со своим молодым коллегой Рикардо Родригесом (Ricardo Rodriguеs) представил доклад, касающийся непосредственной оценки эффективности корпоративного управления. Они провели сравнительное исследование оценки эффективности различных практик и теоретических моделей корпоративного управления на примере компаний Великобритании и Португалии. Янике Расмуссен (Janicke Rasmussen) из Норвежской школь менеджмента (BI Norwegian School of Management) рассмотрел оценку эффективности совета директоров как меру (единииу измерения) эффективности корпоративного управления.

Помимо работ, изучающих корпоративное управление компанией в целом, в ходе конференции были представлены результаты исследований, связанных непосредственно с составом и деятельностью совета директоров. Представитель Пражского университета экономики (Prague University of Economics) Мали Милан продемонстрировал результатьл сравнительного анализа структуры совета директоров в некоммерческих организациях. Работы Даниэля Йохансона и Катарины Штергрен (Johanson Daniel, Katarina Østergren) из Норвежской школь экономики и организации бизнеса (Norwegian School of Economics and Business Administration), а также Яри Канкаанпаa (Jari Kankaanраa), представителя Tampere University, посвящены изучению структуры совета директоров с точки зрения присутствия независимых директоров.

Большинство работ, связанных с исследованием деятельности совета директоров, изучают эффективность его деятельности и влияние его деятельности на результать компании. Так, Томас Штегер (Tomas Steger) из Чемнитского технологического университета (Chemnitz University of Technology) представил интересные результатьл деятельности наблюдательных советов директоров в немецких крупных компаниях. Бегонья Наваллас (Begon'a Navallas) из Автономного университета Maдрида (Madrid Autonoтоus University) совместно с Аной Жиберт Клемент (Ana Gisbert Clemente) продемонстрировала результаты исследования корпоративного управления в котируемых испанских компаниях.

Димитриос Георгакакис (Dimitrios Georgakakis) совместно с Доктором Димитриосом Куфопулосом (Dimitrios Koufopoulos) из бизнес-иколь Брунельского университета (Великобритания) продемонстрировали результать исследования зависимости между характеристиками совета директоров и организационной эффективности на примере некоммерческих и государственных организаций здравоохранения.

Стоит отметить наличие работ, посвященных проблемам корпоративной сочииальной ответственности.

Шерон Кэмn (Sharon Кетр) из Swinburne University of Technology, Австралия, 
рассматривала корпоративное управление и корпоративную социиальную ответственность одновременно. Как результат работы она представила так называемые «уроки» сочиальной ответственности.

Наш дискуссионный обзор структурирован следуюшчим образом. Вначале мьл остановимся на отдельных работах, посвященных различнылм подходам к анализу корпоративного управления: обсудим эволюцию моделей корпоративного управления и частные случаи из практики. Далее мы перейдем к рассмотрению работ, посвященных проблемам корпоративного управления на развиваюшихся рынках. Завершая тематику обобщенного взгляда на корпоративное управление, мы разберем несколько работ, посвященных влиянию различных аспектов управления на корпоративную эффективность. Во втором блоке обзора, посвященном советам директоров, мьл остановимся как на эффективности работы советов, так и на особенностях их работь в некоммерческих организациях.

\section{Модели корпоративного управления: направления развития}

\section{Акционеры или все стейкхолдеры?}

Корпоративное управление привлекало внимание исследователей разнообразием вопросов, требующих анализа. В результате возникали многочисленные исследования, академические дискуссии, демонстрирующие различные подходы к исследованию проблем корпоративного управления. Авторы докладов на международной конференции также обращают на это внимание. Например, исследование Анны Торсел (Anna Thorsell), представляющей бизнес-школу Умеа из Швеции (Umeå School of Business, Sweden), посвящено нахождению возможности для компромисса между двумя моделями корпоративного управления: акционеров и стейкхолдеров ${ }^{74}$. В качестве примера подобного компромисса автор рассматривает Швецию. С одной стороны, Швецию можно охарактеризовать как страну, придерживающуюся модели акционеров, где следование интересам последних выступает в качестве основополагающей обязанности совета директоров, а рынок капитала довольно ликвиден и предоставляет возможности для проведения сделок корпоративного контроля. В пользу данной модели говорит Кодекс корпоративного управления Швеции. С другой стороны, существуют и факты, говорящие в пользу поддержания модели стейкхолдеров. К таковым относятся, например, нахождение блокирующего пакета акций многих котирующихся шведских компаний у институциональных инвесторов и богатых семей, участие персонала корпораций в советах директоров, поощрение присутствия независимых директоров, а также надежные гарантии миноритарным акционерам.

Анализ «серединного пути» (middle road) Швеции позволил Анне Торсон заключить, что сочетание рыночно ориентированной англо-саксонской модели (акционерной) и европейской модели, принимающей во внимание интересы стейкхолдеров, приводит к устранению широко обсуждаемых в научной литературе недостатков каждой из моделей. Так, автор считает, что подобной комбинацией можно избежать недостаточного развития и свободы рынка корпоративного контроля, свойственного модели акционеров, а также укрепления прав собственности миноритарных акционеров, что невозможно в рамках следования исключительно модели стейкхолдеров. Таким образом, пример Швеции демонстрирует достижение максимизации выгод всех заинтересованных сторон, равно как и развитие рынка корпоративного контроля, полученное в результате комбинации двух моделей корпоративного управления.

Еще одним важнейшим механизмом регулирования корпоративного управления

${ }^{74}$ Полное название доклада «Shareholder versus Stakeholder models of corporate governance: Sweden’s middle road». 
выделяют вознаграждение менеджеров. Наиболее популярной теоретической основой, объясняющей данный механизм, является агентская теория. Решение агентской проблемы может быть осуществлено с помощью инструмента стимулирования крупных компаний и контроля над мелкими.

Паоло Ди Тома (Paolo Di Toma), Университет Модена, и Риджио Эмилиа (University of Modena and Reggio Emilia), Италия, представили доклад «Стратегическое ориентирование и корпоративное управление: концептуальная роль структуры собственности». Работа автора представляет собой комплексный обзор исследований по вопросам корпоративного управления с акцентом на возникновение агентской проблемы. Несмотря на то что данный вопрос широко обсуждается в финансовой литературе на протяжении последних десятилетий, в последнее время наблюдается возрастающая критика предпосылок моделей «принципал - агент». Так, проанализировав такие классические работы, как Фама [Fата, 1980], Дженсен [Jensen, 1993], автор заключает, что данные работы фокусируются полностью на проблеме «принципал - агент», забывая о таких концептуальных вопросах, как различия корпоративного управления в зависимости от типа организаций, национальности, институциональной среды. Таким образом, целью исследования Паоло ди Тома стал обзор и систематизация тех работ, которые расширяют границы изучения агентской проблемы, включая в рассмотрение дополнительные факторы. Автор утверждает, что проблема «принципал - агента» в основном анализирует крупные и зрелые компании, в то время как размер компании также не менее важен. Исследование [Huse, 2005; Zahra \& Pearce, 1989] кроме размера фирмы указывает и на такие ситуационные переменные, как национальные, культурные и географические различия. Также Паоло ди Тома обращает внимание на важность таких параметров, как отрасль, структура собственности, жизненный цикл и длительность пребывания в должности генерального директора.

Однако особое внимание автор уделяет структуре собственности, рассматривая тип собственности как ключевую переменную, способную повлиять на механизм корпоративного управления в целом. Например, структура собственности влияет на структуру совета директоров, хотя может быть и противоположный случай, когда совету директоров необходимо менять структуру собственности, чтобы следовать стратегии компании. Таким образом, структура собственности может быть как некоторым ограничением, так и зависимой переменной, при формировании корпоративного управления компании [Huse, 2007].

С другой стороны, когда система корпоративного управления не позволяет собственникам влиять на решения членов совета директоров либо сами собственники не заинтересованы в деятельности компании, влияние структуры собственности становится слабее и совет директоров полностью берет на себя управление компанией и выбор стратегии дальнейшего развития [Pozen, 1994, Short, Keasey, 1997]. Подобные явления могут наблюдаться в компаниях, находящихся в собственности у государства. Однако большинство случаев показывают существование прямого влияния структуры собственности на принятие стратегических решений компании.

В связи с этим автор заключает, что развитие теоретического анализа проблем корпоративного управления с включением большего числа переменных, в том числе относящихся к структуре собственности, может привести к новым результатам, стимулирующим развитие теорий корпоративного управления. Не менее существенными могут быть и прикладные результаты, способные повлиять на эффективность корпоративного управления и выявить необходимые меры регулирования.

В противовес популярности агентской теории в объяснении взаимодействия советов директоров и владельцев компании, Ксавьер Баетен (Xavier Baeten) из Бельгийской школы менеджмента «Влерик Левен Джент» (Vlerick Leuven Gent Management School, Belgium), автор доклада, представил многоуровневый подход к анализу вознаграждения менеджеров. По его мнению, использование только агентской теории затрудняет установление связи между эффективностью компании и вознаграждениями менеджеров из-за жесткости 
предпосылок. У автора вызывает сомнения допущение «узкой модели человека», которая предполагает несклонность индивида к риску, что часто не выполняется в эмпирических исследованиях. Баетен акцентирует внимание на распространенности агентской теории в условиях индивидуализма, что предполагает англо-саксонская система управления и культура. Система корпоративного управления континентальной Европы и Японии встречают ограничения в применении агентского подхода в объяснении взаимосвязи вознаграждения менеджеров и эффективности компании. Работа Баетена посвящена обзору теорий, которые лежали в основе академических и эмпирических исследований. Автор осознает необходимость системного подхода, заключающегося в уменьшении «несоциального» характера рациональной агентской теории. Автор привел статистику в отношении применения различных теорий исследования. Он обратил внимание, что после 2000 года методология исследования не предполагает использования единственной теории. Несмотря на данный факт, из 68 изученных им работ в 70\% случаев агентская теория преобладала в работах. Менеджериальная и институциональная теории были распространены в 30 и 26\% случаев соответственно. В докладе Баетен ставил целью разработать интегрированный теоретический подход к объяснению практики формирования вознаграждения менеджеров. Он считает, что данный подход позволит не только объяснить связь между системой вознаграждения менеджеров и эффективностью компании, но и систематизировать результаты полученных ранее исследований в отношении структуры пакета вознаграждения, разницу между вознаграждениями менеджеров и работников среднего звена. В докладе автора упомянуты 18 теорий формирования вознаграждения менеджеров, которые были использованы в исследованиях по экономике, психологии, социологии.

Теории были разделены на четыре группы:

- исследование контролирующей функции;

- рыночный подход;

- поведенческий подход;

- системный анализ.

К первой группе относятся исследования, сфокусированные на проблеме несоответствия целей менеджеров и собственников фирмы. Решение данной проблемы автор видит в институциональной теории контрактов. Требуется создать такие полные контракты, которые бы предотвратили оппортунистическое поведение менеджеров при исполнении своих функций. Этот подход позволяет решить агентскую проблему.

Вторая группа теорий рассматривает вознаграждение менеджеров с точки зрения спроса и предложения. Автор отнес к этой группе, например, теорию рынка труда, теорию человеческого капитала.

Третью группу составляют теории, включающие в рассмотрение социальные и психологические факторы. В результате автор сформировал поведенческий подход к изучению корпоративного управления. В статье Баетен обсуждает такие теории, как теория ожиданий, теория социального сравнения, психологическая контрактная теория.

Под системным анализом автор подразумевает изучение как характеристик фирмы (размера, отрасли, структуры собственности), так и национального институционального контекста (юридической основы, национальной культуры, систем корпоративного управления). Институциональная и системная теории относятся к этому подходу.

Эффективность корпоративного управления может объясняться не только с позиции теоретического обоснования. В настоящее время бизнес-среда такова, что принятие стратегических решений требует большей ответственности менеджмента. Недостаточное внимание к оценке возможных последствий принятия решений и неэффективный рискменеджмент может привести к понижению финансовой эффективности и, как следствие, потере конкурентного преимущества фирмы. Доминико Пероцци (Domenico Perozzi), PhD студент факультета экономики итальянского университета Дж.Д. Аннунцио Киети-Пескара (University «G. D’Annunzio» Chieti - Pescara (Italy)), и Лоренцо Лучанетти (Lorenzo

\section{Выпуск \#4(8), 2008 \\ (C) Электронный журнал Корпоративные Финансы, 2008}


Lucianetti), исследователь кафедры количественных методов и экономической теории, продемонстрировали интегрирование концепции риск-менеджмента в метод оценки уровня управления, основанный на большом количестве критериев (Balanced Scorecard, BSC). Данный инструмент анализа, по утверждению авторов, позволяет обнаруживать, измерять, управлять рисками, а также сообщать о них более эффективно на уровне советов директоров. Наиболее известный подход к анализу корпоративного управления с позиции концепции риск-менеджмента (ERM) предполагает, что фирма должна управлять стратегическими рисками наряду со страховыми и финансовыми. Таким образом, докладчики утверждают, что выбор ключевых критериев в BSC (key performance indicators, KPIs) и их использование в традиционном риск-менеджменте позволяет советам директоров стимулировать управление эффективностью компании, повысить вероятность достижения стратегических целей компании и создавать стоимость на уровне отдельной бизнес-единицы и макроуровне компании в целом.

Пероцци и Лучанетти синтезировали результаты своего исследования в четырех направлениях. Эффективная система управления рисками позволяет менеджменту и советам директоров разрабатывать оптимальный способ действий компании в условиях неопределенности, чтобы увеличить возможности фирмы создавать стоимость, балансируя между стремлением к росту компании и ее прибыльности.

Система риск-менеджмента в совокупности с инструментами оценки эффективности, $\mathrm{BSC}$, позволяют проанализировать и вовремя предупредить причины заниженных показателей прибыльности в сравнении с ожидаемыми. Кроме того, на уровне советов директоров рассмотренная авторами доклада интегрированная система риск-менеджмента способствует приобретению большей уверенности. В результате может быть создана более эффективная система мер борьбы с возникающими проблемами неопределенности. В заключение авторы акцентируют внимание на вкладе подхода ERM-BSC в образование интегрированного потока информации по сравнению с однонаправленным потоком информации сверху вниз.

\section{Корпоративное управление на развивающихся рынках: Европа и Азия}

Отдельно стоит выделить исследования, в которых обсуждаются вопросы корпоративного управления на развивающихся рынках. Авторы докладов акцентируют внимание на особенностях анализа рынков, функционирующих в условиях различной институциональной среды. Данный раздел нашей работы посвящен сравнению подходов к исследованию корпоративного управления европейских и азиатских стран. Так, Марк Франц Уол (Mike Franz Wahl), представитель Школы экономики и бизнес-администрирования Таллиннского технологического университета (School of Economics and Business Administration, Tallinn University of Technology), считает, что создание стоимости фирмы в долгосрочном периоде является ключевой целью деятельности советов директоров, как фактора эффективности компании и реализации цели максимизации богатства владельцев фирмы. Статья Уола рассматривает практические и теоретические аспекты исследования структуры собственности и представляет эмпирические результаты исследования практики корпоративного управления в Эстонии.

При выполнении данной задачи автор фокусировался на выделении детерминантов качественного корпоративного управления в эстонских компаниях. Исследование докладчика носит многоуровневый характер. Агентская теория [Jensen \& Meckling, 1976) лежит в основе анализа структуры собственности первого индивидуального уровня. Теория позволяет понять взаимосвязь между структурой собственности и структурой совета директоров, а также его участие в процессе принятия решения. На уровне фирмы используется теория стейкхолдера [Freeman, 1984], предполагающая объединение интересов собственников с целью создания стоимости. Наличие взаимосвязи между компанией и организационной средой, в которой она функционирует, требует применения 
эволюционного подхода.

Автор обращает внимание на особенность эстонской экономики, связанной с ее командно-административным управлением до 1990-х годов. В связи с этим в Эстонии насчитывается всего 17 компаний, отвечающих критерию публичности (возможности продажи ценных бумаг на открытом рынке посредством фондовой биржи). В результате в анализ были включены также компании, торгующиеся за пределами фондовой биржи (over the counter). Уол выделяет особенную роль наблюдательного совета директоров как влияющую на эффективность его деятельности и компании в целом. Эмпирическое исследование докладчика основано на 134 опросных листах, в которых требовалось дать оценку значимости и степени удовлетворенности деятельностью наблюдательного совета директоров. Автор ставит себе целью сравнить результаты своего исследования с результатами, полученными членами Международной исследовательской сети корпоративного управления (IFPM), которые изучали практику корпоративного управления в других странах Европы, США, Австралии. Выводы, к которым пришли авторы в данных исследованиях, должны были стать индикатором, относительно которого можно было определить сильные и слабые стороны деятельности советов директоров. Марк Франц Уол приводит в заключение доклада результаты исследования. Средний уровень удовлетворенности деятельностью советов директоров равен 3,97 (то есть в среднем удовлетворены). По выводам автора, наиболее сильными сторонами деятельности советов директоров являются преданность фирме, кооперация, готовность работы в команде, мотивация, быстрые и правильные решения и т.д. Докладчик выделил области для развития, такие как международные связи, риск-менеджмент, финансовые и макроэкономические знания и т.д. В заключение доклада Марк Франц Уол обозначил возможности для дальнейшего исследования: выполнение обязанностей в соответствии с принципами открытости и честности, мотивацию различных групп собственников к контролю и управлению.

Сушил Ханна (Sushil Khanna), профессор Индийского института менеджмента в Калькутте, и Прадиот Сен (Pradyot K. Sen), профессор университета в Цинцинатти, описали проблему корпоративного управления в Индии в докладе «Сущность проблемы корпоративного управления: теория и практика на примере Индии». Данная проблема возникла в Индии со времени существования управляющих агентств (managing agencies) и не была связана с вопросом разделения собственности и контроля, как условиях современного рынка капитала. В Индии была разработана сложная система мер государственного контроля, заменяющая рыночный механизм, что и породило проблему корпоративного управления, называемую проблемой бизнес-групп. Имея дешевые ресурсы, бизнес-группы стали объектом внимания глобальных компаний. Изменения правил корпоративного управления в области слияний и поглощений и начало недружественных рыночных поглощений в условиях либерального режима стали импульсом к попыткам усиления контроля доминирующего собственника, появлению семейного бизнеса. Такой нематериальный актив, как репутация фирмы, связанная с семейным именем, позволяет снизить издержки контрактов, усилить эффективность, выгоды от которой получают все владельцы фирмы.

Так, докладчики рассмотрели два кейса. В первом кейсе авторы привели пример группы компаний Tata, которая использовала политику перекрестных инвестиций для усиления контроля, что привело к выигрышу мажоритарных и миноритарных акционеров. Во втором кейсе Хана и Сен рассматривают ситуацию, с которой столкнулась группа компаний Mafatlal. B отличие от Tata, использование Mafatlal перекрестных инвестиций с целью усиления своего контроля привело к финансовому кризису. По словам авторов, причиной кризиса явились действия группы, направленные против повышения благосостояния владельцев фирмы, в частности иностранных партнеров в этой группе компаний. В докладе были рассмотрены вопросы функционирования бизнес-групп и осуществления перекрестных инвестиций. Главной проблемой является справедливое 
вознаграждение главного владельца бизнеса. Авторами было отмечено, что непропорциональное распределение прав контроля между владельцами фирмы может служить им косвенным вознаграждением. Такая внутренняя диверсификация является лучшим решением проблемы, чем недиверсифицированное владение единственным собственником.

\section{Корпоративное управление и моделирование эффективности компании}

Комплексный подход к моделированию корпоративной эффективности был представлен в работе Ирины Ивашковской и Анастасии Степановой на тему «Влияет ли корпоративная финансовая архитектура на эффективность компании?». Использованное в работе инновационное понятие финансовой архитектуры введено в обращение Стюартом Майерсом [Myers, 1999]. Финансовая архитектура обозначает комбинацию различных факторов внутренней среды корпорации, в том числе структуру собственности, финансирования и мотивации стейкхолдеров. Этот подход существенно пересекается с концепцией изучения влияния корпоративного управления на эффективность деятельности компаний, поскольку как аспекты финансовой архитектуры мы рассматриваем структуру собственности, деятельность совета директоров, структуру капитала и пр.

Как структура собственности, так и деятельность совета директоров рассматривается авторами с точки зрения агентских проблем, что подводит нас к изучению мотиваций стейкхолдеров. В работе сделана попытка изучить агентские конфликты между инсайдерами и акционерами, стратегами и миноритариями, собственниками, аффилированными с государством, и частными лицами. Рассмотрим классический конфликт между менеджерами и акционерами. Каким образом возникают агентские конфликты? Проблема - в разных целевых функциях агентов. Менеджер, чьи доходы напрямую не связаны с ростом стоимости компании, не будет стремиться к максимизации ее стоимости, что является основной целью акционеров. Наиболее популярное решение проблемы - передача небольшого пакета акции в руки менеджмента.

Однако эта проблема - наиболее изученная из всего огромного спектра проблем, связанных со структурой собственности, и, тем не менее, дающая противоречивые результаты на различных выборках. Ученые взялись за разрешение этой проблемы еще в середине прошлого века, а в 1976 году Jensen \& Meckling смоделировали влияние пакета акций в руках менеджмента на корпоративную эффективность. После выхода в свет статьи Морка [Morck, Shleifer \& Vishny, 1988] работы по данной тематике стало возможно объединить в три научные школы. Одни авторы отвергают гипотезу существования зависимости между пакетом акций в руках менеджеров и корпоративной эффективностью; другие утверждают, что собственность менеджеров положительно влияет на эффективность деятельности компании, увеличивая мотивацию к максимизации стоимости компании. Третий тип исследований позволил показать немонотонное, U-образное влияние, положительное для небольших пакетов акций в руках менеджеров и отрицательное для больших пакетов.

Ивашковская и Степанова модифицировали взгляд на данную проблему и перешли к рассмотрению конфликта между миноритариями и акционерами-инсайдерами, то есть акционерами, вовлеченными в процесс корпоративного управления. Авторами была предложена гипотеза о позитивном влиянии пакета акций в руках акционеров, вовлеченных в процесс управления, на корпоративную эффективность. Кого же стоит отнести к таким акционерам? Авторы работы включили в данный показатель всех стратегических инвесторов, государство в случае владения крупными пакетами акций, менеджеров, а также финансовые институты, когда их пакет акций превышает $10-15 \%$, что делает инвестицию стратегически важной для института.

Помимо этого Ивашковская и Степанова предположили наличие существенного, но разнонаправленного влияния пакета акций в руках государства на эффективность, в 
зависимости от страновых особенностей.

Как еще один аспект финансовой архитектуры, в работе рассматривается вопрос о влиянии степени независимости совета директоров на корпоративную эффективность. В модель включен также показатель структуры капитала, измеренный как соотношение всей суммы долга компании к еe активам. Исследователи также контролируют ряд индивидуальных характеристик компании, таких как размер, отрасль, темп роста и прочее.

Модель была верифицирована на данных более 170 компаний из 8 европейских стран, в том числе России, Германии, Италии, Испании, Польши, Румынии и т.д. Помимо обобщенной выборки были использованы три подвыборки: по развитым странам, по растущим рынкам капитала и по России.

Особенно привлекательными для дискуссии выглядят результаты верификации модели. Во-первых, была подтверждена гипотеза о позитивном влиянии пакета акций в руках вовлеченных в управление акционеров на корпоративную эффективность. Авторы показали, что рост пакета акций на $1 \%$ приводит к росту корпоративной эффективности, измеренной показателем Q-Тобина, на $0.43 \%$. Заметим, что на подвыборках из российских и восточноевропейских компаний вместо переменной, равной пакету акций в руках вовлеченных инвесторов, была использована фиктивная переменная, равная единице при наличии в структуре собственности блокхолдеров. Для развивающихся рынков было выявлено значимо положительное влияние показателя на корпоративную эффективность. Для России подобной зависимости обнаружено не было.

В чем заключается проблема? Вероятнее всего, размеры подвыборок слишком малы и данные слишком неоднородны, для того чтобы выявить изучаемую зависимость.

Государственная собственность сильно коррелирована с показателем собственности вовлеченных в управление инвесторов, поэтому в целях избегания мультиколлинеарности показатель государственной собственности не включался в модель одновременно с показателем собственности вовлеченных инвесторов. В результате построения параллельной модели с учетом государственной собственности авторы продемонстрировали негативное влияние государственной собственности на корпоративную эффективность, однако этот результат не подтвердился на более мелких подвыборках.

Рассмотрим результаты, полученные Ивашковской и Степановой относительно влияния на эффективность доли независимых директоров в совете. Авторы доказали на обобщенной выборке, что наличие в совете директоров независимых директоров положительно влияет на корпоративную эффективность, измеренную показателем QТобина. Этот результат был подтвержден также на российской подвыборке и на подвыборке из компаний развивающихся стран. Но доля независимых директоров оказалась незначимой, что позволяет сделать вывод о целесообразности небольшого числа независимых директоров. Можно также предположить, что отсутствие этой зависимости в развитых странах объясняется характером политики: в большинстве стран котирующиеся компании обязаны иметь независимых директоров в совете, что делает бессмысленным проверку данной фиктивной переменной.

Что касается еще одного блока финансовой архитектуры, структуры капитала, в исследовании было обнаружено значимое негативное влияние долговой нагрузки на корпоративную эффективность. Подобные факты могут быть объяснены превышением компаниями оптимального уровня долга.

Все регрессии, построенные авторами, имеют объясняющую силу от 33 до 47\%. Помимо классической модели с экзогенными переменными, двигаясь в русле современных исследований корпоративного управления, Ивашковская и Степанова проверили гипотезу о потенциальной эндогенности структуры капитала, а потом и структуры собственности. В результате они смогли отклонить гипотезу об эндогенности и продемонстрировать логичность предпосылок об экзогенности переменных. Такой результат находится в противоречии с выводами некоторых исследований, например Химмельберг [Himmelberg et al., 1999], однако нужно не забывать о том, что характер переменной может зависеть от 
структуры выборки, то есть от страновых или секторальных особенностей, а также от опущения некоторых значимых переменных в конкретной верифицируемой модели.

\section{Эффективна или деструктивна глобализация моделей корпоративного управления?}

Интересные выводы были представлены Фелицио Жозе Аугусто (Felicio Jose Augusto) и Рикардо Родригесом (Ricardo Rodrigues) из Школы єкономики и менеджмента (ISEG School of Economics And Management) Технического университета Лиссабона (Technical University of Lisbon). В их работе произведен сравнительный анализ результатов применения двух классических моделей корпоративного управления. Авторы сравнивают эффективность корпоративного управления в соответствии с англо-американской моделью на данных компаний из Великобритании и результаты применения континентальноевропейской (или японской) модели управления, которую они изучают на португальской эмпирике.

Напомним, что споры о применении старой англо-американской модели, которая основывается исключительно на интересах акционеров, как единственных собственников компании, начались достаточно давно и привели к возникновению альтернативной модели корпоративного управления. Альтернатива - континентальноевропейская модель, применяемая также в Японии, которая базируется на балансировании интересов всех стейкхолдеров, иначе говоря, всех лиц, так или иначе вовлеченных в процесс жизнедеятельности компании. Среди стейкхолдеров - акционеры, менеджеры, кредиторы, работники, поставщики и т.д.

В последние годы в результате процессов глобализации зашла речь о конвергенции англо-американской и континентальноевропейской моделей корпоративного управления. По мнению авторов, это может выразиться в необоснованном снижении учета страновой специфики, в частности специфики государственного регулирования и особенностей бизнессреды. Что происходит, когда мы забываем о страновой специфике? Если отвлечься от корпоративного управления, можно вспомнить случаи внедрения американской модели пенсионной системы в некоторых восточноевропейских стран, которые завершились провалом именно из-за того, что были недостаточно учтены геополитические и этнографические особенности. Не может ли глобализация в данном случае негативно сказаться на эффективности корпоративного управления?

В попытке ответить на этот вопрос Аугусто и Родригес задались целью выявить сходство и различие детерминант корпоративной эффективности для разных моделей корпоративного управления. Ученые построили обобщенную модель корпоративной эффективности, включающую такие переменные, как доля независимых директоров в совете директоров, разделение ролей СЕО и председателя совета директоров, концентрация голосующих акций и прочие. В качестве прокси-переменных для корпоративной эффективности авторы используют как рыночные (Q-Тобина), так и бухгалтерские переменные (ROE, темп роста продаж).

Модель была верифицирована на подвыборках компаний с Лондонской биржи (London Stock Exchange) и с биржи Euronext (Лиссабон), а также на объединенной выборке. Предварительные выводы подтверждают гипотезу о прежнем различии бизнес-среды и чрезмерной конвергенции моделей корпоративного управления.

На наш взгляд, конвергенция моделей корпоративного управления не может не происходить в реалиях сегодняшнего дня. Не секрет, что сегодня ассимиляция происходит даже между самими финансовыми сообществами разных стран: вспомним количество экспатов в российских инвестиционных банках и количество русских, работающих в Европе, Америке и Азии. С учетом этого процесса нельзя отрицать конвергенцию моделей корпоративного управления, несмотря на то что в бизнесе уровень ассимиляции ниже, чем в инвестиционно-банковской индустрии. Ряд ключевых российских компаний управляется эмигрантами: так, например, председателем правления компании «Вимм-Билль-Данн» уже третий год является Тони Деннис Майер, приехавший в Россию 15 лет назад. На наш взгляд, 
конвергенция моделей имеет место, но в первую очередь происходит не на «исторической родине», а на растущих рынках капитала, не имеющих собственных традиций корпоративного управления. Разумеется, российский и ряд других растущих рынков достаточно интегрированы в мировое сообщество, чтобы оказывать обратное влияние на западные модели корпоративного управления, но этот процесс протекает медленно и не оказывает значительного влияния на эффективность сегодня.

Противоположного взгляда на эволюцию моделей корпоративного управления в связке с корпоративной эффективностью придерживается Манли Фу (Manli $\mathrm{Fu}$ ), научный сотрудник и аспирант Института лидерства и человеческих ресурсов (Institute of Leadership and Human Resources) Университета Сент-Галлена в Швейцарии (University of St. Gallen). B своей работе на тему «Эффективность корпоративного управления в китайских коммерческих банках» она категорично высказывается о возможности саморегулировании системы финансовых рынков и утверждает, что сегодняшнее кризисное состояние глобальной экономики спровоцировано «жадностью банкиров, финансовых институтов и материально обеспеченного класса людей» [Manli Fu, 2008].

По мнению автора, корпоративное управление может носить исключительно ситуационный характер, что позволяет сделать предположение о наличии глубинных различий в применяемых моделях корпоративного управления не только в разных странах, но и в различных секторах экономики. В качестве примера Манли Фу использует банковский сектор Китая, чтобы продемонстрировать особенности корпоративного управления и сделать ряд рекомендаций по совершенствованию системы.

Изучение ряда коммерческих банков, деятельности их советов директоров, их корпоративной этики и прочего позволили автору вывести ряд рекомендаций относительно повышения эффективности процесса корпоративного управления. Одной из наиболее интересных рекомендаций представляется наращивание роли наблюдательного совета во внутреннем мониторинге деятельности банков, что поддерживается также рекомендацией по разработке новой организационной структуры и новой структуры корпоративного управления, нацеленной непосредственно на внутренний контроль компании. Применительно к банковской сфере Китая, Манли Фу также настаивает на усилении акцента на корпоративной этике, дью-дилидженса, компенсационной политике, системе санкций, а также государственного регулирования случаев получения взяток.

\section{Эффективны ли советы директоров?}

Деятельность советов директоров является одним из доминирующих направлений исследования в современной академической литературе. Часть исследований сфокусирована на анализе влияния структуры советов директоров на эффективность компании [Bonn et al., 2004; Tian and Lau, 2001; Dalton et al., 1998]. В условиях увеличивающейся интернализации возрастает значимость исследований, направленных на выявление влияния характеристик советов директоров на эффективность компаний, функционирующих в таких условиях.

\section{Случай семейных компаний}

Попытка провести такое исследование была предпринята Нисаном Селеклер-Гоксеном (Nisan Selekler-Goksen), доцентом кафедры международной торговли университета Богазичи

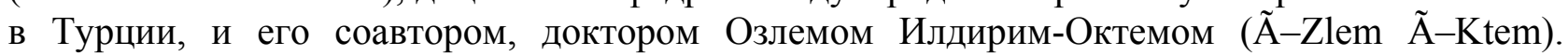
Авторами был представлен доклад «Влияние эффективности совета директоров на интернализацию компаний, входящих в крупные бизнес-группы». В работе исследуется зависимость между характеристиками советов директоров и эффективностью интернализации компаний бизнес-групп в условиях развивающегося рынка Турции. Авторы отмечают, что семейные бизнес-группы являются доминирующей формой организации бизнеса в развивающихся экономиках. Стремление к интернализации и становлению более 
открытой системы рынков определяет одно из стратегических решений фирмы, которое принимается советами директоров. Данная организационная структура рассматривается как инструмент контроля и координации компаний семейных бизнес-групп.

Теоретической основой исследования Илдрим-Октема и Селеклера-Гоксена является подход, основанный на видении фирмы с точки зрения ее ресурсной теории. Согласно описанному докладчиками подходу, фирма имеет конкурентное преимущество благодаря контролируемым ею ценным, редким ресурсам. С одной стороны, эффективность интернализации фирмы зависит от ее способности аккумулировать и соединять физический, организационный и человеческий капитал. С другой - авторы указывают на связь между характеристиками человеческих ресурсов фирмы и способностью реализовывать международные стратегии. Илдрим и Селеклер обозначили факторы, влияющие на эффективность интернализации, такие как возраст менеджеров, полученное образование, уровень владения иностранными языками, способность устанавливать связи. Поскольку советы директоров являются источниками человеческого капитала, может быть установлена связь между их характеристиками и эффективностью интернализации компании.

Докладчиками были сформулированы четыре гипотезы в исследовании:

1. Полученное членами совета директоров образование будет выше в фирмах с большей эффективностью интернализации.

2. Количество членов советов директоров, обладающих способностью анализировать специфику зарубежных рынков, будет выше в фирмах с большей эффективностью интернализации.

3. Средний возраст членов советов директоров ниже в фирмах с большей эффективностью интернализации;

4. Присутствие членов семьи будет выше в фирмах с большей эффективностью интернализации.

Исследование проводилось на выборке котирующихся компаний (аффилированных) шести бизнес групп на основе данных годовых отчетов компаний. Была построена эконометрическая модель, в которой в качестве зависимой переменной эффективности интернализации оценивались интенсивность экспорта и прямые иностранные инвестиции. Факторами в модели выступали полученное членами совета директоров образование, понимание специфики зарубежных рынков, возраст и степень присутствия членов семьи в совете директоров.

В заключение доклада Илдрим и Селеклер приводят результаты исследования. Авторами было установлено, что оценка эффективности интернализации с помощью доли экспорта не позволяет выявить влияние характеристик советов директоров. Верной аппроксимацией эффективности являются прямые иностранные инвестиции в дочерние компании за рубежом. Такую неоднозначную зависимость авторы объясняют тем, что крупные турецкие бизнес-группы приобрели значительный опыт выхода на международный рынок с помощью экспорта. Решение этой задачи лежит на менеджменте компании, как менее рисковая операция. Как наиболее рисковый шаг, осуществление прямых иностранных инвестиций является решением стратегической задачи советов директоров. Таким образом, сформулированные авторами гипотезы не отвергаются при анализе влияния характеристик советов директоров на эффективность фирмы, измеренную с помощью переменной прямых иностранных инвестиций в дочерние компании бизнес-групп Турции.

\section{Двухуровневая система советов директоров: есть ли смысл в наблюдательном совете?}

Большинство исследований, посвященных анализу корпоративного управления и роли советов директоров, опирается на агентскую теорию и ее предпосылки [Daily et al., 2003; Finkelstein and Mooney 2003; Roberts et al., 2005]. Представители Технического университета Кемниц Томас Штегер (Thomas Steger), доцент кафедры Европейского менеджмента, и Ян Штеффен (Jahn Steffen), исследователь департамента маркетинга, считают невозможным 
применение единого подхода к исследованиям. По их мнению, следует учитывать культурные особенности и различную институциональную среду, в которой существуют компании.

В докладе, посвященном роли и рентабельности наблюдательных советов(Are they worth the money they get? Role taking and contribution of German supervisory boards) авторы обращают внимание на особенность корпоративного управления в Германии, заключающуюся в выделении исполнительного и наблюдательного советов директоров. Исполнительной функцией является управление компанией. наблюдательный совет директоров назначает исполнительный совет директоров и контролирует его. Цель данного исследования - выявить роль наблюдательного совета директоров и оценить влияние результатов его деятельности на эффективность компании. За период 2006-2007 годов были опрошены 116 немецких частных компаний.

Авторы оценили влияние стратегической, контролирующей и вспомогательной функций на эффективность деятельности советов директоров и компании в целом. Вспомогательная функция включала в себя представление интересов фирмы и деятельность по консультированию исполнительного директора и топ-менеджеров. Стратегическую функцию Штегер и Ян охарактеризовали так: определение и разработка стратегии фирмы. Контролирующая роль представляет собой администрирование и внутренний контроль фирмы, за исключением контроля топ-менеджеров. В модели их исследования были оценены композитные индексы на базе исполняемых советом директоров функций. Оцениваемая эффективность советов директоров основывалась на субъективном мнении респондентов о качестве работы советов директоров. Финансовая эффективность измерялась показателем отдачи от продаж (ROS).

Исследователи оценивали зависимость эффективности деятельности советов директоров от композитных индексов выполняемых функций. Они обнаружили, что контролирующая и вспомогательная роли влияют в значительной степени на эффективность деятельности советов директоров. Контролирующая функция как в крупных, так ив мелких компаниях имеет более значительное влияние, чем вспомогательная, что согласуется с ранними исследованиями [Jürgens \& Lippert, 2005]. Вспомогательная функция оказывает влияние в мелких компаниях. Стратегическая функция имеет значение только для выборки крупных фирм - с занятостью более 500 человек. Авторами также был сделан вывод о том, что выполняемые наблюдательным советом функции не оказывают влияния на эффективность компании. Вывод, полученный авторами, подтверждает тот факт, что ответственность за эффективность компании принимает на себя исполнительный совет директоров [Brauchitsch 2003, Deloitte 2004]. Переложение функций на наблюдательный совет директоров не приводит к значимой зависимости между эффективностью его деятельности и компании.

\section{Концепция независимости, или жизнь в рамках кодекса}

Регулирование корпоративного управления в большей степени сконцентрировано на совете директоров. Концепция независимости директоров стала основополагающей в кодексе советов директоров. Новые правила листинга на американских фондовых биржах основаны на предположении о независимости советов директоров.

Концепция независимости являлась предметом исследования в докладе Даниэля Йохансона (Daniel Johanson) и Катарины Штергрен (Katarina Ostergren), исследователей из Норвежской школы экономики и бизнес-администрирования. Докладчики анализировали концепцию независимости советов директоров как базис регулирования корпоративного управления в различных институциональных средах.

В первой части работы авторы акцентируют внимание на теоретическом обосновании концепции независимости, историческом развитии концепции и проводят ее эмпирическое исследование. Так, авторы утверждают, что на концепцию независимости в большой 
степени повлияли агентская теория и финансовый учет. Эти теории не дают информации об изменении структуры кодексов советов директоров. В качестве альтернативы Йохансон и Остергрен рассматривали институциональную теорию менеджмента, которая позволяет проводить анализ в различных институциональных средах, объясняя, как кодекс переводится и используется в различных странах. Во второй части работы представлено исследование роли независимых директоров в совете на примере Великобритании и скандинавских стран. Анализируя кодексы, отчеты стран и характеристики институционального устройства, авторы пытались определить роль независимости советов директоров в кодексах советов директоров.

Авторы обратили внимание на взаимосвязанность советов директоров и институциональной среды. Было выделено четыре институциональных фактора, в большей степени определяющих концепцию независимости советов директоров:

1. Структура советов директоров.

2. Структура собственности.

3. Цель образования корпорации.

4. Наличие социальных сетей.

Были обнаружены различные эффекты указанных факторов в Великобритании и странах Скандинавии. Концепция независимости имеет центральное значение в скандинавских странах, и рекомендации относительно концепции независимости сходны с теми, что постулируются в Британском кодексе (2008). Такой результат не согласуется со сформулированной докладчиками гипотезой о том, что в скандинавских странах должна наблюдаться меньшая значимость концепции независимости. С институциональной точки зрения возможное объяснение заключается в том, что в странах признается законным следование положениям кодекса в глазах зарубежных институциональных инвесторов и фондовых бирж. Авторы работы выдвигают предположение о том, что такое следование законам не изменит установленную в странах Скандинавии практику корпоративного управления. Отделение формальной структуры от неформальной позволит компаниям поддерживать эффективность наряду со следованием кодексу советов директоров.

\section{Независимые директора и прозрачность компании}

Исследователи кафедры бухгалтерского учета Бегонья Наваллос (Begoña Navallas Labat) и Аной Гисберт Клименте (Ana Gisbert Clemente) из Автономного университета Мадрида проводили эмпирическое исследование на выборке котирующихся на бирже испанских фирм. Их доклад «Корпоративное управление и добровольное раскрытие информации котирующимися испанскими компаниями» был посвящен выявлению характера влияния факторов корпоративного управления на качество информации, добровольно раскрываемой испанскими компаниями в ежегодных отчетах. Исследование проводилось на основе индекса, построенного на выборке 62 испанских публичных котирующихся компаний. Индекс состоял из 76 элементов, раскрытых по корпоративной социальной ответственности, нематериальным активам, финансовой и нефинансовой информации, и будущих перспектив.

Аналитический инструментарий исследования Наваллос и Гисберт основывался на применении описательной статистики и эконометрического подхода. Авторы в своем исследовании подтверждают факты теории, что независимые директора значительно влияют на качество добровольно раскрываемой среди испанских фирм информации. В результате посредством предоставления дополнительной информации, публикуемой в финансовых отчетах, уменьшается информационная асимметрия. По результатам исследования Наваллос и Гисберт, «серые» директора не влияют на объем раскрываемой информации, но оказывают прямое воздействие на раскрытие обязательной финансовой информации, в частности, на качество заработанных доходов. 


\section{Роль независимых директоров: взгляд с точки зрения корпоративной социальной ответственности}

Доклад Шэрон Кэмп (Sharon Kemp, PhD), доцента Суинбернского технологического университета в Австралии (Swinburne University of Technology), посвящен рассмотрению вопросов корпоративной социальной ответственности. В своем докладе «Корпоративное управление и корпоративная социальная ответственность: уроки Страны Оз», автор продолжает широко обсуждаемую в научной литературе тему необходимости преследования компаниями не только финансовых, но и социальных целей. Для определения необходимых мер, которых должна придерживаться компания, чтобы, с одной стороны, достичь своих финансовых целей, а с другой стороны, соблюсти баланс общественных затрат и выгод, Шэрон Кэмп вспоминает страну Оз американского писателя Лаймена Фрэнка Баума. Данная метафора позволяет автору проводить параллели между необходимостью для членов советов директоров и топ-менеджмента найти баланса между разумом, эмоциями и целями и попытками героев сказки обрести с помощью Волшебника Страны Оз такие качеств, как ум, сердце и мужество. В сказке герои обнаружили, что Волшебник не обладает силой, которая может помочь им приобрести данные качества; однако, пройдя через ряд испытаний и осознав, что ум, сердце и мужество и так им присущи, они нашли тот необходимый баланс, который делает их сильными. Аналогично компании необходимо найти баланс между разумом, эмоциями и целями, для того чтобы обеспечить базис для социально ответственного поведения компании. Исследование Шэрон Кэмп представляет собой итоги серии интервью с членами советов директоров пяти австралийских компаний, входящих в рейтинг 50 крупнейших компаний Австралии, проведенных с целью выявить меры, необходимые для укрепления корпоративной социальной ответственности компаний. В ходе интервью автор пытался обсудить с членами советов директоров следующие три вопроса:

- Чего стоит ожидать от совета директоров?

- Каким образом должны функционировать советы директоров?

- Какие наиболее существенные действия должны совершаться советом директоров и его членами для эффективной работы?

Как результат проведенных интервью, Шэрон Кэмп сформулировала ряд рекомендаций, которых должны придерживаться компании для соблюдения обсуждаемого баланса и осознания корпоративной социальной ответственности. В первую очередь, для развития в компании принципов корпоративной социальной ответственности необходимо, чтобы генеральный директор, совет директоров и высший менеджмент компании определили и установили данные принципы. Принципы и ценности социальной корпоративной ответственности должны быть внедрены в деятельность компании таким образом, чтобы они были понятны персоналу и могли быть использованы в его повседневной деятельности, ввиду чего компаниям стоит привлекать к разработке соответствующих процедур по установлению социально ответственного поведения ключевых стейкхолдеров. Поддержание контактов со стейкхолдерами и стремление к максимальной открытости информации о компании также указываются автором как необходимые меры укрепления уверенности в надежности и социальной ориентированности компании. Члены совета директоров должны прежде всего четко понимать прошлое компании, настоящее ее положение и перспективы развития. Однако важен также и состав совета директоров. По мнению авторов, существенны такие параметры, как наличие в совете директоров представителей с различным опытом для диверсификации совокупных навыков, необходимых для эффективной наблюдательной и консультативной деятельности. Автор подчеркивает, что простого комбинирования внешних и внутренних директоров в составе совета директоров для достижения подобного эффекта недостаточно. Тем не менее Шэрон Кэмп утверждает, что наличие независимых директоров необходимо для уравновешивания влияния, оказываемого на деятельность компании исполнительным директором. Для достижения же поставленных компанией целей исполнительный директор и совет 
директоров должны сотрудничать в атмосфере взаимного доверия, уверенности и осознания способствования единому делу. Последний совет автора также относится к взаимоотношениям исполнительного директора и совета директоров, констатируя важность установления традиции работы над постоянным совершенствованием. Стоит отметить, что, несмотря на то что исследование базируется на серии интервью с членами советов директоров пяти австралийских компаний, автор указывает на возможность применения результатов исследования членами советов директоров и в других странах.

\section{Иностранцы в совете директоров: есть ли смысл?}

Если в докладе Шэрон Кэмп затрагивалась тема роли независимых членов в составе совета директоров, то исследование Изабелы Калядкевич (Dr. Izabela Koladkiewicz) сосредоточено на рассмотрении возрастающей роли иностранных членов советов директоров и наблюдательных советов. В своей работе «Взгляд иностранных членов на наблюдательные советы польских публичных компаний» автор отмечает очевидные преимущества наличия в наблюдательных советах польских публичных компаний иностранных членов, состоящие в первую очередь в обогащении компаний опытом и знаниями иностранных коллег. Более того, иностранные представители могут дать более независимую оценку деятельности компании, посмотреть на нее со стороны. Однако в целях получения более подробной информации о мнении иностранных членов наблюдательных советов о деятельности советов Центром исследований по менеджменту Университета Козмински (Польша) и Польским институтом директоров было проведено исследование на основе анкетирования. Анкеты рассылались в 26 компаний, входящих в индексы WIG 20 и WIG 40 Варшавской биржи, в составе наблюдательных советов которых в общей сложности присутствуют 99 иностранных членов. Анкета состояла из 27 закрытых вопросов, направленных на оценивание решений, принятых польскими компаниями по проблемам корпоративного управления, а также эффективности деятельности наблюдательных советов в целом. К целям исследователей также относились определение важности персонального опыта членов наблюдательного совета, а также выявление мнения участников опроса относительно качества потоков информации между наблюдательным и исполнительным советами компании.

Согласно результатам, полученным в ходе обработки присланных заполненных анкет, польские наблюдательные советы в настоящее время в большей степени представляют собой органы контроля, демонстрирующие крайне скромный уровень активности. Деятельность наблюдательных советов сосредоточена в основном на двух направлениях: мониторинге текущей деятельности исполнительного совета и деятельности, оговоренной в коммерческом кодексе компании. Среди положительных сторон наблюдательных советов респонденты отметили хороший уровень знаний по корпоративному управлению, демонстрируемый польскими членами наблюдательных советов, а также процесс передачи информации между наблюдательным советом и менеджментом компании. Не менее существенным положительным фактом, по мнению анкетируемых, являются уставы наблюдательных советов, исполнительных советов и генеральных ассамблей акционеров, не только предоставляющих информацию о компании, но и позволяющих иностранцам занять места в польских советах. По мнению автора, данные сильные стороны наблюдательных советов в Польше во многом обязаны недавно начатым реформам корпоративного управления, сформулированным в Принципах лучшей практики в публичных компаниях 2002 года [The Principles of Vest Practice in Public Companies 2002]. Несмотря на указанную положительную оценку, данную информационным потокам внутри польских компаний, иностранные члены наблюдательных советов пришли к выводу о необходимости установления более тесного сотрудничества между наблюдательными советами и менеджментом.

К сожалению, результаты, представленные Изабелой Колядкевич, нельзя отнести к 
репрезентативным ввиду обработки только 14 заполненных и присланных анкет, однако даже столь небольшое количество респондентов дает полезное представление о взгляде иностранных представителей, обладающих совершенно другим опытом и потому, по мнению автора, наиболее независимым взглядом, на эффективность деятельности польских наблюдательных советов. Так, если даже результаты столь малой выборки говорят о необходимости укрепления взаимоотношений между менеджментом и наблюдательным советом, стимулирования большей активности наблюдательного совета, осознания членами наблюдательного совета своей ответственности как чего-то большего, чем просто мониторинг, то проблема несовершенства наблюдательных советов в Польше в настоящее время действительно актуальна. Однако не стоит столь безоговорочно принимать деятельность иностранных членов наблюдательных советов как более профессиональную и полезную для функционирования компании. В действительности важно понимать, во скольких наблюдательных советах состоят респонденты. Автор просит обратить внимание, что даже очень опытный профессионал, состоящий в нескольких советах, а также имеющий основное место работы, бесспорно, не может оказывать должного внимания конкретной компании ввиду серьезной загруженности. Более того, не стоит забывать о крайне низкой степени заинтересованности иностранных членов наблюдательных советов в исследовании, выраженной в 15\%-ном уровне ответивших на вопросы анкеты респондентов.

\section{Неэффективность совета директоров: все дело в женщинах!}

Интересное исследование, посвященное проблемам эффективности работы советов директоров в организациях здравоохранения, было представлено греческими учеными доктором Димитриосом Куфопулосом (Dimitrios Koufopoulos) из Брунельской бизнес-школы (Brunel Business School, Brunel University) и Димитриосом Георгакакисом (Georgakakis Dimitrios) из «Гносис Менеджмент Конталтенс» (Gnosis Management Consultants), Великобритания.

Исследователи собрали данные 120 греческих государственных больниц путем интервьюирования СЕО. Им было предложено оценить эффективность деятельности совета директоров, а также организационную эффективность больниц. В каждом из блоков авторы, используя классификацию Чейта [Chait et al., 1993], выделили по несколько аспектов. Так, эффективность совета директоров была оценена исходя из:

1) контекстуального аспекта: советом директоров разбирается в организационном контексте учреждения;

2) образовательного аспекта: совет выполняет образовательную функцию;

3) аналитического аспекта: совет способен находить решения сложных комплексных задач;

4) коммуникативного аспекта: совет представляет собой сплоченную команду;

5) политического аспекта: совет поддерживает отношения с представителями власти;

6) стратегического аспекта: совет осуществляет стратегическое планирование.

Организационная эффективность была определена из финансовой, операционной и собственно организационной эффективностей.

Нас, конечно, больше интересует эффективность деятельности совета директоров. И несмотря на то что авторы говорят о существенном различии между детерминантами эффективности корпоративного управления для частных компаний и для государственных учреждений, дискуссия относительно полученных выводов небезынтересна.

Результаты исследования таковы. Во-первых, авторы выявили, что позитивно влияет на эффективность совета директоров частота проведения заседаний. Отметим, что средняя частота проведения заседаний по выборке зафиксирована на уровне три раза в месяц, что само по себе немало. Например, в России типичная практика проведения советов - два раза в месяц. И тем не менее в греческих учреждениях здравоохранения большая частота дает 
большую эффективность управления. Попробуем объяснить этот результат с точки зрения вопросов, решаемых советом директоров. Рискнем предположить, что совет директоров в греческой больнице гораздо больше вовлечен в принятие операционных, не стратегических решений. Тогда, безусловно, нужно чаще встречаться, ведь серьезные операционные вопросы требуют очень часто незамедлительного решения, и решение таких проблем через неделю может потерять всякий смысл.

Во-вторых, авторы, как и многие предыдущие исследователи, выявили негативное влияние размера совета директоров на его эффективность. Это обуславливается тем, что чем больше людей в совете, тем меньшую ответственность чувствует каждый; кроме того, достигнуть соглашения в «раздутых» советах также проблематично.

И наконец, авторы показали, что число женщин в совете директоров значимо негативно влияет на его эффективность, несмотря на очень небольшое количество женщин в советах директоров в среднем (2,1 женщины при среднем размере совета в 7,3 человека). Авторы не объясняют данный результат, но одно из возможных объяснений, предложенных Захрой и Стентеном [Zahra \& Stanton, 1988], заключается в том, что мужчины способны привлекать больше ресурсов для работы учреждения, чем женщины.

В заключение стоит упомянуть о том, что Куфопулос и Георгакакис получили, что нефинансовая эффективность коррелирует с образовательным, стратегическим и контекстуальным аспектом, тогда как финансовая эффективность зависит от коммуникативного, аналитического и образовательного аспектов. Таким образом, было продемонстрировано, что финансовая и нефинансовая эффективность определяется разными факторами, и единственное исключение - образовательная функция совета директоров, которая позитивно влияет на любую форму эффективности.

\section{Европейские советы директоров: сравнительный анализ тенденций развития}

Интересная для нашей дискуссии работа была представлена Миланом Мали (Milan Maly), профессором менеджмента из Пражского єкономического университета (University of Economics, Prague). Автор провел сравнительный анализ структур советов директоров некоммерческих организаций в Чехии, Франции, Великобритании и других странах Европы. Работа интересна еще и тем, что эмпирическая часть проведена так же, как у Куфопулоса, на данных учреждений здравоохранения.

Хотя речь идет об управлении некоммерческими организациями, выявленные тенденции интересны в дискуссионных целях и для частных компаний. Данные по организациям были собраны восемью студенческими командами из ряда европейских стран.

Основной инновационный вывод исследования заключается в том, что межстрановые различия не очень значительны, а тенденции эволюции советов директоров практически идентичны в разных странах. Остановимся на некоторых выделенных тенденциях.

Во-первых, во всех странах, и особенно в Чехии, растет роль частных компаний в изучаемом секторе здравоохранения. Во-вторых, очевидна тенденция перехода к количественному измерению эффективности деятельности учреждения. Эта же тенденция наблюдается, как нам известно, и в частных компаниях.

В-третьих, высокими темпами увеличивается роль внутреннего контроля и мониторинга, о чем мы уже рассуждали в первой главе обзора, когда речь шла о корпоративном управлении в китайских коммерческих банках. В странах с двухуровневой системой советов растет роль наблюдательных советов и менее значимой становится роль исполнительных советов. В отличие от частных компаний, в учреждениях здравоохранения не практикуется включение в совет директоров работников учреждения, хотя опыт ряда европейских стран (в частности, Франции) говорит о целесообразности такой практики.

И в завершение необходимо сказать о качественной тенденции, выявленной Миланом Мали. Автор выявляет тенденцию увеличения роли всех стейкхолдеров в процессах принятия решений, что особенно заметно в процессах назначения директоров и 
менеджмента, а также в степени раскрытия подобной информации широкой публике. Другими словами, речь идет о стремлении некоммерческих организаций к модели корпоративного управления, основанной на интересах стейкхолдеров, а не только акционеров. Этот вывод несколько противоречит утверждению о глобализации моделей корпоративного управления, которую мы рассмотрели в первой главе, поскольку европейские некоммерческие учреждения принимают «домашнюю», восточноевропейскую модель управления, используемую частными компаниями.

\section{Финансовый кризис и активность совета директоров: новые альтернативы?}

Ингли Корал (Ingley Coral), Технологический университет Окленда, Новая Зеландия, представила доклад на тему «Кредитный кризис, активные инвесторы и стратегия корпорации: означает ли это появление акционеров в залах заседаний советов директоров?» Исследование Ингли Корал, проведенное совместно с Дженс Мюллер (Jens Mueller) и Грэйм Кокс (Graeme Cocks), посвящено рассмотрению текущей роли акционеров и возможного усиления их влияния в советах директоров компаний в Новой Зеландии. Исторически публичные компании в странах Британского содружества наций, в состав которых входит и Новая Зеландия, придерживаются в основном одноярусной модели совета директоров, исключающей вовлечение акционеров. Участие акционеров тем более исключено в вопросах формулирования стратегии корпорации и принятия корпоративных решений. Новая Зеландия, естественно, не единственная страна, отстающая в развитии ответственности перед стейкхолдерами компании. Корал Ингли указывает на работы Дулевич и Херберт [Dulewicz, Herbert, 2003], а также Стайлс и Тэйлор [Stiles, Taylor, 2001], исследующие подобные проблемы в Великобритании. В то же время в Европе и Японии представительство персонала и акционеров в составе советов директоров не только встречается часто, но в некоторых случаях является и необходимым законодательным условием функционирования крупных компаний.

Авторы исследования полагают, что в настоящее время есть ряд факторов, способствующих развитию активности инвесторов в Новой Зеландии. К данным факторам, в первую очередь, относятся изменяющиеся правила корпоративного управления, подразумевающие предоставление существенно больших прав инвесторам в вопросах выбора членов советов директоров, возрастающую роль пенсионных планов и хедж-фондов. Во-вторых, вовлеченность стейкхолдеров компании может быть увеличена как результат кредитного кризиса, приведшего к слабости рынка акций. Соответственно авторы исследования решили проверить, действительно ли есть признаки усиления роли акционеров в советах директоров компаний Новой Зеландии. Для реализации данной цели было проведено онлайн-анкетирование акционеров, исполнительных директоров и членов советов директоров крупного числа компаний Новой Зеландии. Всего было получено 1800 ответов, в дополнение предыдущего исследования авторов, проведенного в 2006 году (2100 респондентов). В результате обработки анкет было выявлено, что члены советов директоров в Новой Зеландии в последнее время действительно были вынуждены усилить роль социальной корпоративной ответственности и обратить внимание на интересы стейкхолдеров, однако данный аспект не может быть назван ключевым. Более того, процент стейкхолдеров, недостаточно информированных о политике корпоративного управления компании, начиная с 2006 года снижается. Однако было обнаружено, что в небольших компаниях только сейчас начинают появляться независимые члены советов директоров и устанавливаться внутренние процедуры корпоративного управления. Тестирование стандартов корпоративного управления было проведено по нескольким показателям компании: корпоративная стратегия, законность, лидерство, обязательство, устойчивость, дух команды, управление различными взглядами. Исследование показало, что только категория «обязательство» была оценена респондентами на «отлично», чего нельзя сказать о прочих параметрах. Если предыдущие результаты говорили о неких положительных 
изменениях корпоративного управления в Новой Зеландии, последние результаты, очевидно, не согласуются с лучшими практиками и говорят о необходимости последующего развития. По мнению автора доклада, бизнес школы и университеты могут сыграть существенную роль в развитии корпоративной социальной ответственности компаний и требуемых компетенций советов директоров, равно как и менеджмента компаний.

\section{Список литературы}

1. Bonn I, Yoshikawa T., Phan P.P. Effects of board structure on firm performance: A comparison between Japan and Australia // Asian Business and Management. 2004. No.3. P. $105-125$.

2. Brauchitsch E.v. Überwachung der Konzern- und Unternehmensführung durch den Aufsichtsrat - Erfahrungen und aktuelle Praxis aus der Sicht eines Aufsichtsratsvorsitzenden / In M.R. Theisen (Ed.)/ Der Konzern im Umbruch. Stuttgart: Schäffer-Poeschel? 1998 - p. 297-307.

3. Chait R.P., Holland T.P., Taylor Barbara E. The Effective Board of Trustees. Phoenix/ Arizona: Oryx Press, 1993.

4. Dalton D.R., Daily C.M., Ellstrand A.B., Johnson J.L. Meta-analytic reviews of board composition, leadership structure, and financial performance // Strategic Management Journal. 1998. Vol. 19. No. 3. P. 269-290.

5. Deloitte. Entwicklung der Aufsichtsratspraxis in Deutschland. Frankfurt: Deloitte, 2004.

6. Dulewicz V., Herbert P. Does the composition and practice of UK boards bear any raletionship to the performance of listed companies? // Paper presents at the 6-th International Conference on Corporate Covernance and Board Leadership. Henley Management College, UK, 6-8 October, 2003.

7. Fama E.F. Agency problems and the theory of the firm // Journal of Political Economy. 1980. No. 88. P. 288-307.

8. Freeman R. E. Strategic Management: A Stakeholder Approach. Boston: Pitman, 1984.

9. Fu M. Effectiveness of Corporate Governance in Chinese Commercial Banks. Report on 5th workshop on Corporate Governance of European Institute of Advanced Management Studies. Brussels. 27-28 November 2008.

10. Himmelberg C. P., Glenn H. R., Darius P. Understanding the Determinants of Managerial Ownership and the Link between Ownership and Performance // Journal of Financial Economics. 1999. No. 53. P. 353-384.

11. Huse M. Accountability and Creating Accountability: A Framework for Exploring Behavioural Perspectives of Corporate Governance // British Journal of Management. 2005. No. 16. P. S63-S79.

12. Huse M. Boards, Governance and Value Creation, Cambridge: Cambridge University Press, 2007.

13. Jensen M., Meckling W. The Theory of Firm: Managerial Behavior, Agency Costs and Capital Structure // Journal of Financial Economics. 1976. No. 3. P. 305-360.

14. Jensen M.C. The modern industrial revolution, exit and the failure of internal control systems // Journal of Finance. 1993. Vol. 48. No.3. P. 831-880.

15. Jürgens U., Lippert I. Kommunikation und Wissen im Aufsichtsrat: Voraussetzungen und Kriterien gutter Aufsichtsratsarbeit aus der Perspektive leitender Angestellter // Discussion Paper SP III. Berlin: WZB. 2005. No. 301.

16. Morck R., Shleifer A., Vishny R. Management Ownership and Market Valuation: an Empirical Analysis // Journal of Financial Economics. 1988. No. 20. P. 293-315.

17. Myers S. Financial Architecture // European Financial Management. 1999. No. 5. P. 133141.

18. Pozen R. Institutional Investors: the Reluctant Activist // Harvard Business Review. 1994. January - February. 
19. Short H., Keasey K. Institutional Shareholders and Corporate Governance in the United Kingdom / In Keasey K, Thompson, S. \& Wright M. (editors) Corporate Governance. Economic // Management and Financial Issues/ Oxford: Oxford University Press. 1997.

20. Stiles P., Taylor B. Boards at Work: How Directors View their Roles and Responsibilities // Oxford. Oxfors University Press. 2001.

21. Tian J., Lau C.M. Board composition, leadership structure and performance in Chinese shareholding companies // Asia Pacific Journal of Management. 2001. Vol. 18, No. 2, P. $245-263$.

22. Zahra S.A., Stanton W. The implications of board of directors composition for strategy and corporate performance // International Journal of Management. 1988. Vol. 5. No. 2. P. $229-236$. 